\title{
The Genetic Potential of Wheat Resistance to Heavy Metals
}

\author{
R. Alybayeva ${ }^{1, *}$, V. Kruzhaeva ${ }^{2}$, A. Alenova ${ }^{2}$, I. Salmenova ${ }^{2}$, A. Asylbekova ${ }^{2}$, A. Sadyrbaeva ${ }^{2}$ \\ ${ }^{1}$ Department of Biology and Biotechnology, Kazakh National University named after Al-Farabi, Kazakhstan \\ ${ }^{2}$ Department Geography and Nature Management, Kazakh National University named after Al-Farabi, Kazakhstan
}

Copyright $\bigcirc 2016$ by authors, all rights reserved. Authors agree that this article remains permanently open access under the terms of the Creative Commons Attribution License 4.0 International License

\begin{abstract}
The aim of this study was to identify wheat germplasm resistant to heavy metals (zinc and cadmium) that are priority pollutants in eastern Kazakhstan region and identification of donors for breeding and promising forms destined for agricultural production. The objects of research are different genotypes of spring wheat (Triticum aestivum L.) from the collection of the East Kazakhstan Research Institute of Agriculture. Model experiments were performed on 10-days-old sprouts of wheat genotypes, which were grown on nutrient mixtures containing $\mathrm{Cd}$ or $\mathrm{Zn}$ ions. In field experiment plants were grown on scientific test site, under natural environmental pollution in East Kazakhstan region. Heavy metals in soil and in plant samples were determined by atomic absorption spectrophotometry. Experiments and determination of physiological parameters were conducted by the method of field experiment. Research in model experiment has revealed tolerant and sensitive genotypes. The membranes permeability for the electrolyte in a resistant variety changed in a less degree than the more sensitive in both cases is due to effect of cadmium as well as zinc. This fact testifies that stability of plants in general can be caused by resistance of their cellular membranes to the action of stressor. Field experiment showed genotypic differences in the accumulation of cadmium and zinc in the seeds. Identified genotypes that accumulate a minimum amount of cadmium in the seeds can be recommended for further study in breeding process. Also identified genotypes accumulate a minimum amount of zinc in seeds, they can be recommended for further use in breeding for resistance to zinc accumulation in the grain. Research has revealed the most productive varieties of spring wheat. Two varieties of wheat can be recommended for cultivation on soils contaminated with cadmium, as these varieties of spring wheat accumulate least of cadmium in the seeds and at the same time are characterized by high yields and good survival during the spring-summer growing season in a polymetallic contamination of soil.
\end{abstract}

Keywords Wheat, Heavy Metal Resistant Germplasm, Membrane Permeability, Metal Accumulation,
Physiological Parameters, Yield, Promising Forms

\section{Background/ Objectives and Goals}

In Kazakhstan, the development of a powerful industry was based on its rich natural resources. However, the industrial centers are the areas of highest contamination by heavy metals [1]. Sound environmental technologies are crucial to address heavy metal pollution. Development and use of plant varieties characterized by minimal accumulation of heavy metals can provide one such environmental solution.

The available literature data showed that a significant positive correlation between the concentration of heavy metals in the grain and genotypes, indicating the possibility of breeding varieties with a low potential for accumulation of heavy metals [2].

Characterization of heavy metal accumulation in wheat and identification of germplasm resistance to influence of heavy metals is an important step towards the creation and use of wheat varieties resistant to heavy metal pollutions in agricultural production systems. This requires the study of the gene pool of cultivated plants and the selection of donors that accumulate minimum amount of heavy metals and varieties that are promising for cultivation in areas contaminated with heavy metals.

The aim of this study was to identify wheat germplasm resistant to heavy metals (zinc and cadmium), which are important to eastern Kazakhstan region and identification donors for breeding and promising forms of wheat that are resistant to heavy metals and destined for agricultural production.

\section{Methods}

Different genotypes of wheat (Triticum aestivum L.) specific to East Kazakhstan were studied. Experiments were 
carried out using spring wheat varieties of East Kazakhstan Agricultural Research Institute collection: Altai, Ulbinka-25, Zaulbinka, Lyazzat, Glubochanka, Nargiz, Omskaya-18, Samal, Eritorospermum-606, Kutulukskaya.

Model experiments were performed on 10-days-old sprouts of different wheat genotypes, which were grown in 3 replications in nutrient mixtures containing $\mathrm{Cd}$ ions in concentration $40 \mathrm{mg} / 1\left(\mathrm{CdSO}_{4}\right)$ or $\mathrm{Zn}$ in concentration $400 \mathrm{mg} / \mathrm{l}\left(\mathrm{ZnSO}_{4}\right)$. The content of cadmium and zinc in roots and aboveground parts of seedlings was determined. Determination of membrane permeability for electrolytes was performed in 3 replications by conduct metric Dexter method [3]. Weigh leaves $(500 \mathrm{mg})$ immersed for $60-50$ minutes in $180 \mathrm{ml}$ of water with a known conductivity. After exposure exudate was decanted into another glass and conductivity measured by conductivity meter. After the count was poured into the same cup with the sample, brought to a boil, the electrical conductivity of the exudate was determined again. Calculation formula: $\%$ elution electrolytes $=(a: b) \times 100$, where $a-$ conductivity dead tissue, $\mathrm{b}$ - the electrical conductivity of living specimens.

Field studies carried out for the determination of physiological parameters. Plants were grown on scientific test site, under natural environmental pollution, in the suburban area of Ust-Kamenogorsk city, East Kazakhstan region. In field experiment the following physiological parameters were determined: phenological observations, yield, yield structure, the content of cadmium and zinc in seeds. Conducting the experiments and determination of physiological parameters were done in 3 replications by the method of field experiment [4].

Heavy metals (zinc and cadmium) in soil and plant samples were determined by atomic absorption with atomization in flame and graphite furnace on the device AAnalyst 300 of "Perkin Elmer" firm. Sample preparation was carried out using a heating unit «Hot Block» with the addition of concentrated nitric acid and hydrochloric acid at a temperature of $90 \pm 5^{\circ} \mathrm{C}$, in accordance with standard operating procedures. Weighed portion of dried sample (1g) was placed in disposable sample cups; $5 \mathrm{ml}$ of $50 \%$ nitric acid and $0.5 \mathrm{ml}$ of concentrated hydrochloric acid were added. Samples were mixed well to liquid clay condition, covered with a watch glass and placed in a heating block. The sample was heated to a temperature of $90 \pm 5^{\circ} \mathrm{C}$, and evaporated for 10-15 minutes without boiling. Then the sample was cooled, $5 \mathrm{ml}$ concentrated $\mathrm{HNO}_{3}$ were added and heated again for 30 minutes. Content of capacitances were evaporated without boiling at a temperature of $90 \pm 5^{\circ} \mathrm{C}$ for approximately up to $5 \mathrm{ml}$ during 2 hours, avoiding foaming. After that the sample was cooled and the volume was adjusted to $50 \mathrm{ml}$ with deionized water.

To calibrate the device calibration blank have been used, consisting of deionized water and $1 \% \mathrm{HNO}_{3}$ solution and standard samples of the company «High Purity". After calibration of the devise readings of analyzed samples were taken. Accuracy of analysis performance was checked by the screening standard of the company «Merck».

The content of heavy metal in the sample was calculated according to the formula:

$$
C m g / k g=\frac{C \text { device } \times V \text { samp. } \times F D}{M}
$$

wherein

$\mathrm{C}$ device - devise reading $(\mathrm{mg} / \mathrm{l})$;

V samp. - final volume of samples (ml);

FD - dilution factor;

$\mathrm{M}$ - weighed sample $(\mathrm{g})$.

\section{Results}

Pollution, especially chemicals - one of the most powerful factors of destruction of the biosphere components. It is believed that the heavy metals are the most toxic among chemical elements [5-7]. Studies by a number of authors demonstrated that plants grown in contaminated soils, show significant interspecies differences in the response to pollution [6-8]. Some varieties of different species of food crops also show significant differences in resistance to soil contaminants, which indicates the possibility of controlling the technogenic resistance features by breeding method $[9,10]$. Therefore, we investigated the different varieties of spring wheat genotypes in a model experiment to identify that little accumulate heavy metals. The studied varieties further investigated in the field to assess the degree of accumulation of heavy metals in the seeds and evaluate their other important breeding features - productivity, survival in the conditions of the spring-summer growing season.

The study of the regularities of accumulation and distribution of $\mathrm{Zn}$ and $\mathrm{Cd}$ in organs of spring wheat depending on genotypic differences in a model experiment has revealed tolerant and sensitive genotypes.

Investigation of the zinc content in the aerial parts of seedlings of different spring wheat genotypes showed that the smallest accumulation of zinc, at its content in the medium is $400 \mathrm{mg} / \mathrm{l}$, is observed in sprouts of varieties Lyazzat and Samal. The highest zinc content in the aboveground organs observed for plant variety Ulbinka-25 (Figure 1). 


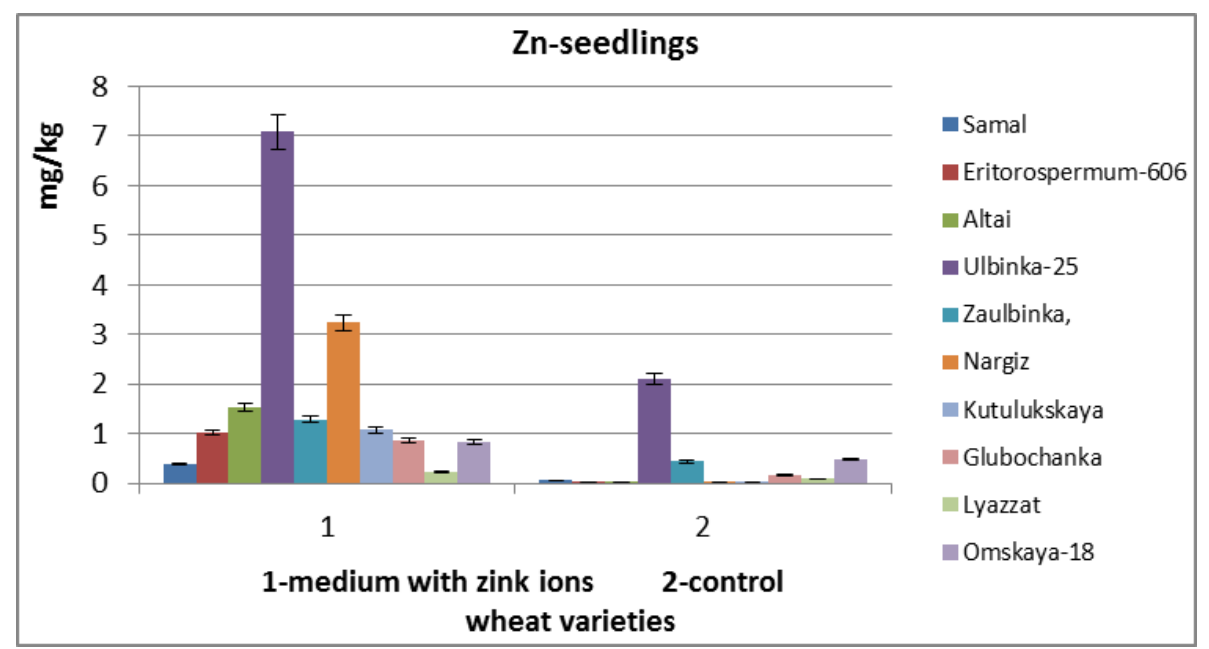

Figure 1. Zinc content in aboveground parts of different spring wheat genotypes in the conditions of contamination of cultivation medium

Investigation of zinc accumulation in plant roots, when its content in the medium is $400 \mathrm{mg} / \mathrm{L}$, showed that the least amount contained in the roots of seedlings of varieties Altai, Lyazzat, Glubochanka and Samal. The highest zinc content in the plants roots observed for variety Ulbinka-25 (Figure 2).

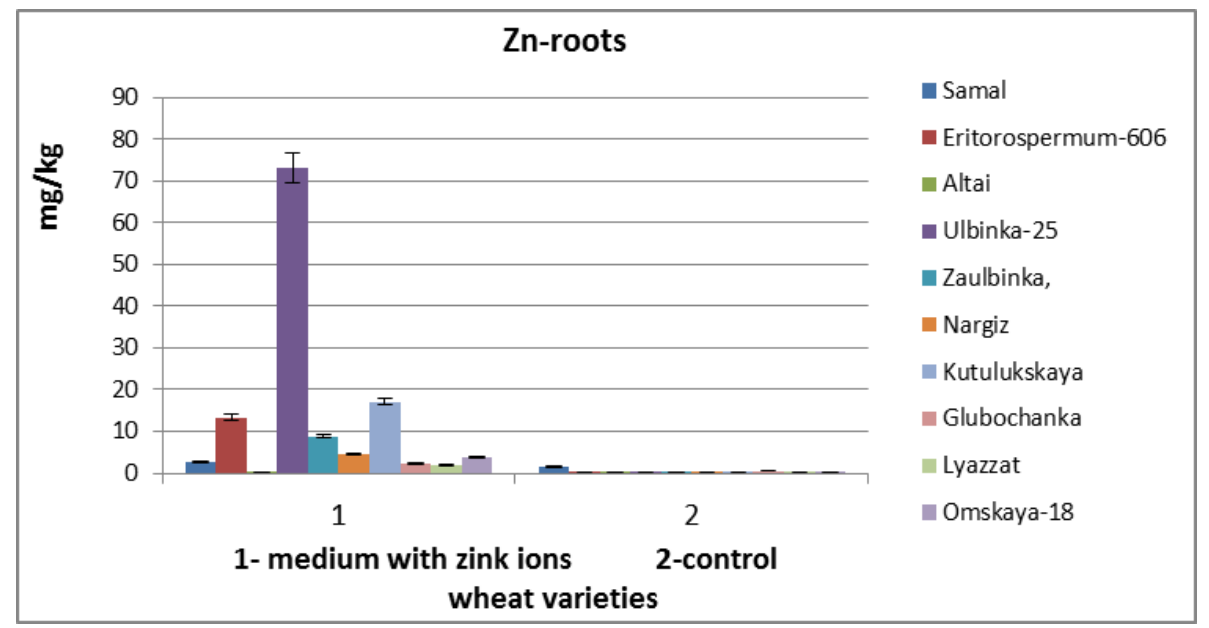

Figure 2. Zinc content in the roots of the different spring wheat genotypes in the conditions of contamination of cultivation medium

According to the study results, the effect of zinc on the growth parameters of the 10-day-old wheat seedlings and as well as the accumulation of zinc in the roots and above-ground parts of plants of different of spring wheat genotypes, we can distinguish the variety Altai as the genotype with the highest root resistance to zinc and varieties Lyazzat and Samal as resistant to the translocation of zinc in the aerial organs.

The content of cadmium in the aerial parts of sprouts of studied spring wheat genotypes showed that at dose $40 \mathrm{mg} / \mathrm{lof}$ cadmium in the growing medium the least amount in above-ground organs accumulate sprouts of spring wheat varieties Lyazzat, Omskaya-18 and Altai. The largest amount of cadmium in the aerial organs, in these experimental conditions, accumulates seedlings of spring wheat variety Erythrospermum-606. The remaining varieties occupy an intermediate position between them (Figure 3). 


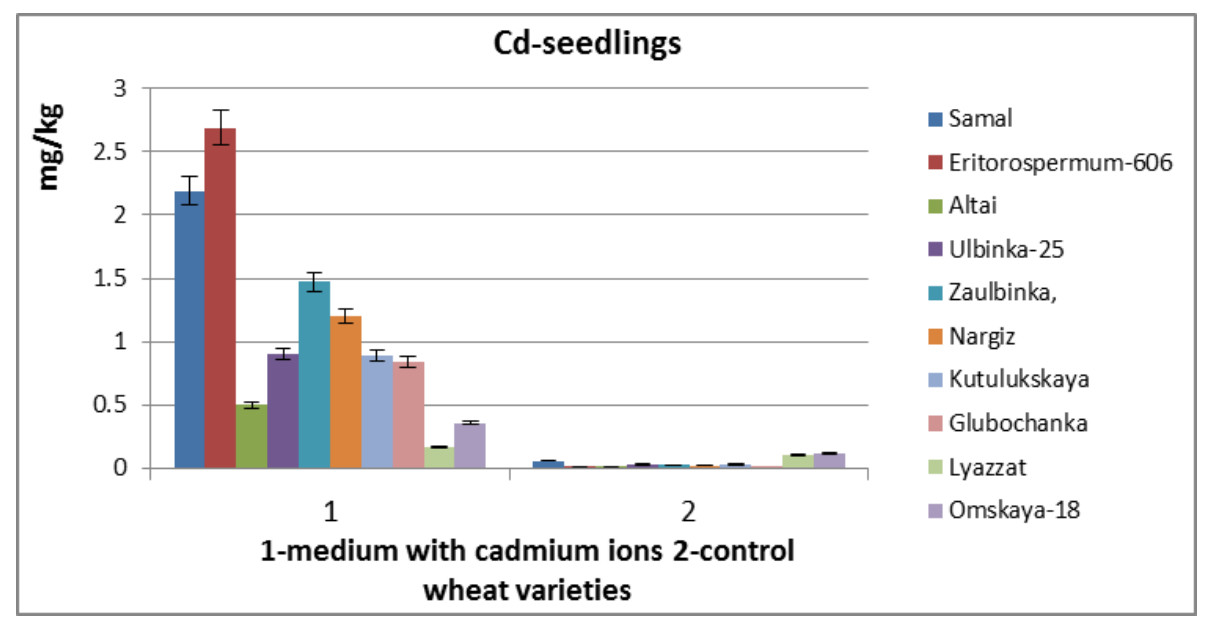

Figure 3. Cadmium contents in the aerial parts of different spring wheat genotypes in the conditions of contamination of cultivation medium

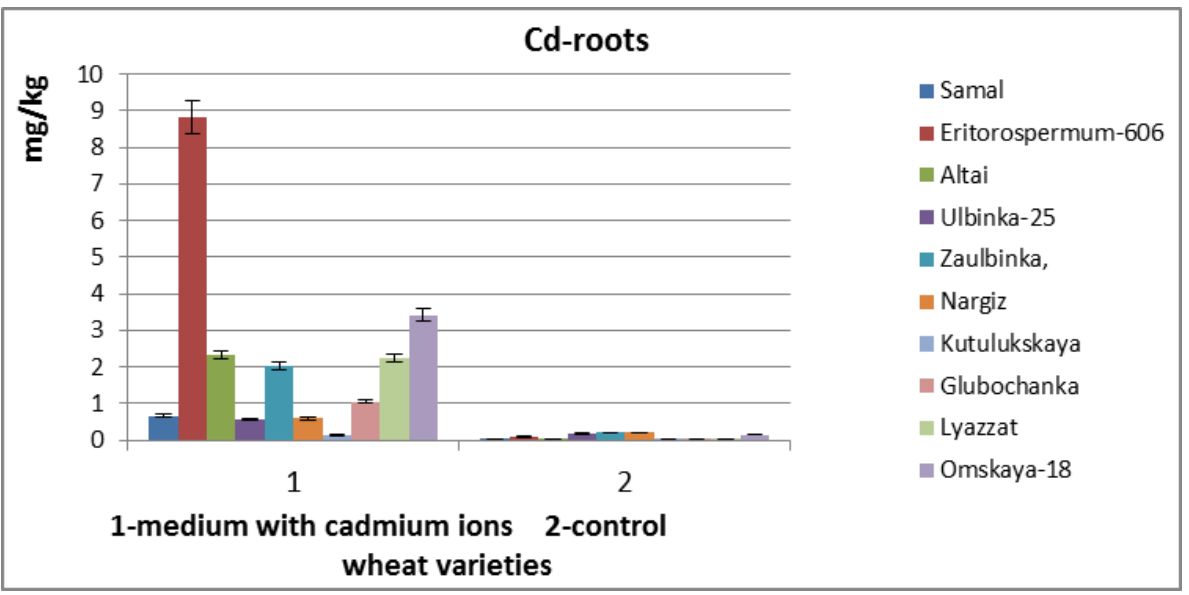

Figure 4. Cadmium content in the roots of the different spring wheat genotypes in the conditions of contamination of cultivation medium

Investigation of cadmium in the roots of spring wheats genotypes showed that at its dose of $40 \mathrm{mg} / \mathrm{l}$ in the growing medium the smallest amount of cadmium is accumulated by spring wheat varieties Kutulukskaya, Nargiz, Ulbinka-25 and Samal. The greatest amounts of cadmium accumulate in the plant roots of the spring wheat variety Erythrospermum-606. The remaining varieties occupy the intermediate position between them (Figure 4).

According to the results of study of cadmium accumulation in the roots and above-ground parts of plants of different spring wheat varieties Kutulukskaya, Nargiz, Ulbinka-25 and Samal can be identified as the genotypes with the greatest root resistance to cadmium and varieties Lyazzat, Omskaya-18 and Altai as the genotypes with resistant to the translocation of cadmium in above-ground organs.

A change in membrane permeability under stress indicates structural adjustment of the membranes, which largely determines the potentially possible mechanisms of plants to withstand adverse environmental factors [11]. Therefore, the permeability of cell membranes of wheat has become the subject of our study. The testing of contrasting on resistance of spring wheat varieties on the permeability of cell membranes was conducted in the laboratory. It is known that the output of the electrolyte is a function of membrane permeability, which in its turn characterizes the degree of its damage [12]. The permeability of plasma membrane for the electrolytes - is an integral indicator of the functional state of plants [13]. The increase the exosmosis of electrolytes under stress reflects many processes, such as increase in desorption of the membrane electrolytes and liberation them in the decay of the labile biological complexes and increase of sorption capacity of protoplasm [14]. Consequently, the genotypes are resistant to adverse environmental factors should have different physical-chemical characteristics of the membrane. Changes in membrane permeability under stress testify about restructuring of the membranes, which largely determines the potentially possible mechanisms of plants to withstand adverse environmental factors. As a result of changes in the permeability of cell membranes under the influence of various factors the amplified output of electrolytes from the cells. The intensity of the secretion of electrolytes depends on the varietal characteristics and age of the plant.

Study of the effect of cadmium ions on cell membrane permeability of the aerial parts of plants of resistant - Altai and sensitive - Erythrospermum-606 wheat genotypes demonstrated that the permeability of cell membranes for 
electrolytes under the action of high concentrations of cadmium (40 mg / L) increases (Table 1).

In winter wheat variety Altai permeability of cell membranes of leaf tissues under the influence of cadmium is increased for $23 \%$ relatively to control. In spring wheat varieties Erythrospermum-606 under the action of cadmium membrane permeability of leaf cells to the electrolyte rises for $75 \%$ (Table 1 ).

Table 1. Influence of cadmium ions on the electrolyte output from leaf tissue of 10-day-old wheat seedlings

\begin{tabular}{|c|c|c|}
\hline Variants & \% output of electrolytes & \% to control \\
\hline \multicolumn{3}{|c|}{ Variety Altai } \\
\hline Control & $2,52 \pm 0,05$ & 100 \\
\hline $\mathrm{Cd} 40 \mathrm{mg} / 1$ & $3,17 \pm 0,01$ & 123 \\
\hline \multicolumn{3}{|c|}{ Variety Erythrospermum } \\
\hline Control & $3,15 \pm 0,01$ & 100 \\
\hline $\mathrm{Cd} 40 \mathrm{mg} / 1$ & $5,52 \pm 0,01$ & 175 \\
\hline
\end{tabular}

Study of the effect of zinc ions in the cell membrane permeability of the aerial parts of plants of resistant - Altai and sensitive - Erythrospermum-606 wheat genotypes demonstrated that the permeability of cell membranes for the electrolyte under the action of high concentrations of zinc $(400 \mathrm{mg} / \mathrm{l})$ increases (Table 2). In the variety of spring wheat Altai permeability of cell membranes of leaf tissues under the influence of zinc increased for $13 \%$ relatively to control. In the winter wheat variety Erythrospermum-606 under the action of zinc leaf cell membrane permeability for the electrolytes was increasing for $45 \%$ (Table 2).
Table 2. Influence of zinc ions on electrolytes output from leaf tissue of 10-day old wheat seedlings

\begin{tabular}{|c|c|c|}
\hline Variants & \% output of electrolytes & \% to control \\
\hline \multicolumn{3}{|c|}{ Variety Altai } \\
\hline Control & $2,52 \pm 0,05$ & 100 \\
\hline Zn $400 \mathrm{mg} / 1$ & $2,84 \pm 0,06$ & 113 \\
\hline \multicolumn{3}{|c|}{ Variety Erythrospermum } \\
\hline Control & $3,15 \pm 0,01$ & 100 \\
\hline Zn $400 \mathrm{mg} / 1$ & $4,63 \pm 0,017$ & 145 \\
\hline
\end{tabular}

It should be noted that the permeability of membranes for the electrolytes in more resistant variety Altai varied in a less degree in comparison with more sensitive - Erythrospermum 606 , as under the action of lead, as well as under the action of zinc. This fact indicates that, as a whole, resistance of the plants may be caused by the resistance of the cell membrane to the action of the stressor. The reason for the strongest suppression of the growth processes in spring wheat variety Erythrospermum-606, as well as the relative stability of the Altai variety to the toxic effects of heavy metals, may be different ability of cell membranes to withstand stress, in particular, to heavy metals.

The next stage of our research was field experiments, as we were interested in the level of accumulation of heavy metals in the commodity part of the wheat - seeds. Our studies of the accumulation of heavy metals in the soil of root zone of different genotypes of winter wheat collection of East Kazakhstan Agricultural Research Institute under natural pollution showed that the content of heavy metals is different (Figure 5, 6).

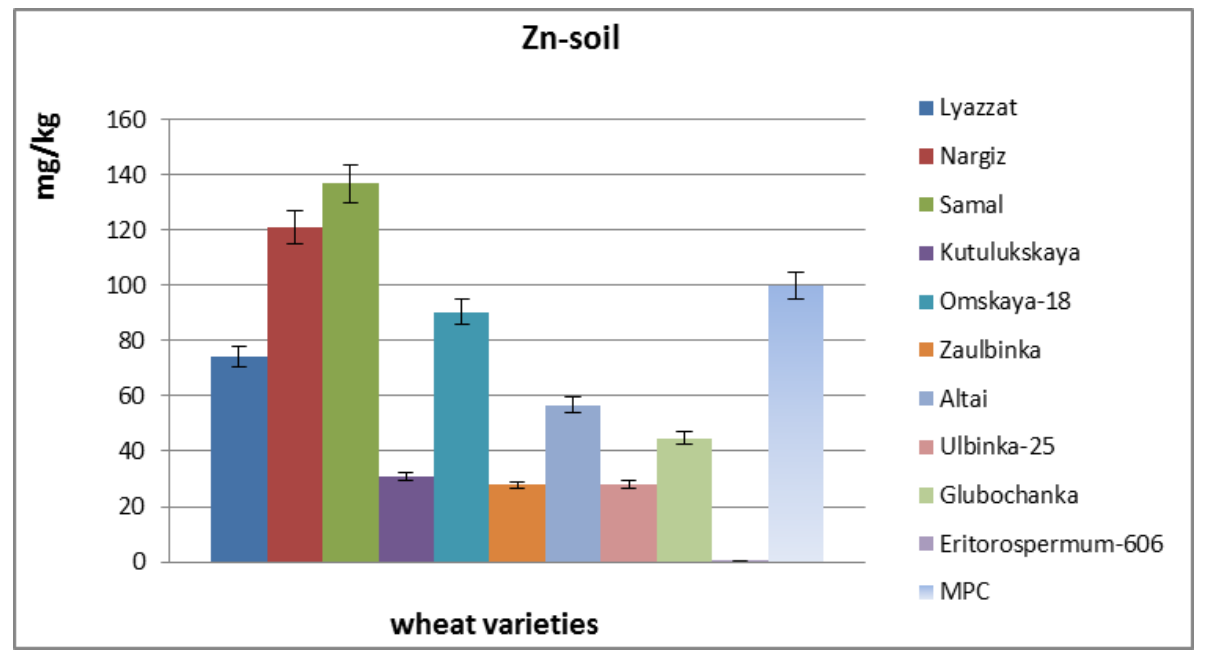

Figure 5. Content of zinc in the root zone soil of studied genotypes $(\mathrm{mg} / \mathrm{kg})$ in relation to the maximum permissible concentration (MPC).

Zinc content exceeds the maximum permissible concentration of the metal only in the root zone soil of varieties Nargis and Samal, in the zones of other varieties such excess is not observed (Figure 5). Thus, the wheat plants are not under stress from increased concentrations of zinc in the soil, except for varieties Samal and Nargiz, but in this case the excess is insignificant.

Investigation of cadmium in the soil of the roots zone of different genotypes of winter wheat showed that the amount of the metal exceeds the maximum permissible concentration in nearly all varieties, except varieties Nargiz and Altay (Figure 6). 


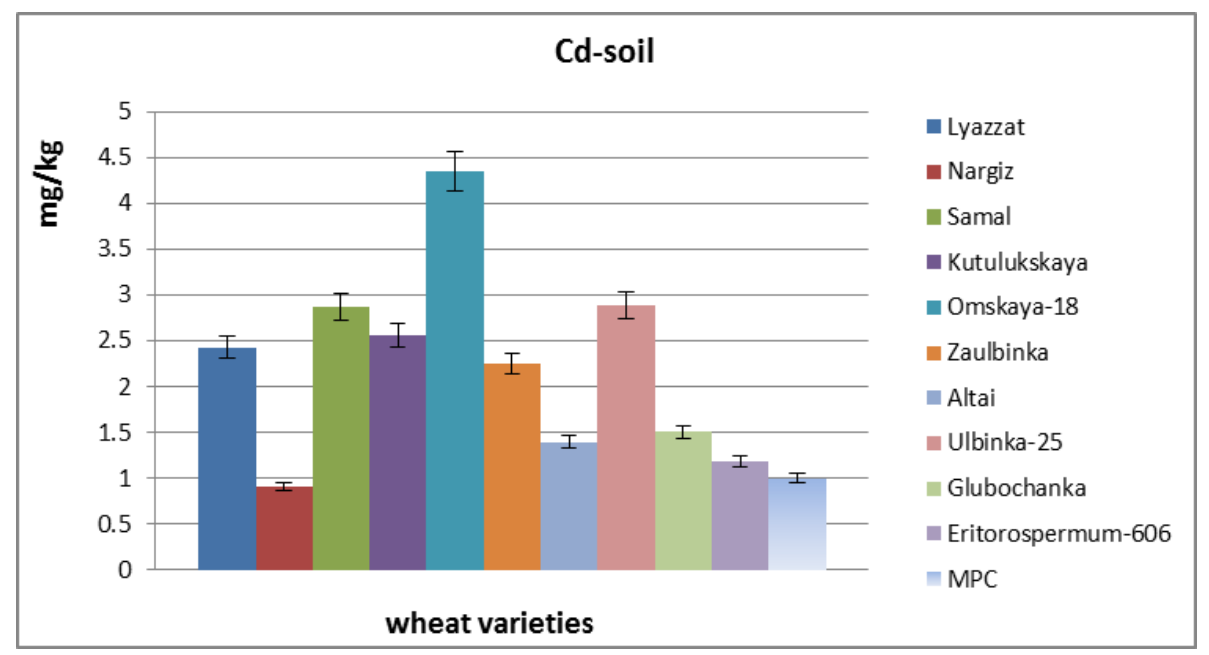

Figure 6. Content of cadmium in the root zone soil of studied genotypes $(\mathrm{mg} / \mathrm{kg})$ in relation to the maximum permissible concentration (MPC).

The scope of excess of MPC is from 1.5 to 4.5 times. The highest excess recorded in the root zone soil of variety Omskaya-18. Thus, the wheat plants are stressed by high concentrations of cadmium in the soil, and this stress is significant. It should be noted also that the study of soil contamination has polymetallic character. The excess of the MPC also observed for metals such as copper and lead.

In this connection, it was of interest to study the parameters of growth and development of these varieties to identify the tolerance to abiotic stress and agronomic resistance of varieties in the conditions of polymetallic stress. This may facilitate the identification of varieties that retain good productivity and at the same time little accumulates heavy metals in the grain.

Investigation of zinc and cadmium in the seeds of winter wheat genotypes is the most important as a grain of wheat is used in the food industry. According to some researchers, the level of heavy metal cadmium in products is the problem of food security. Reduction of cadmium in the grain is one of the priorities of breeding programs [15].

Our research of accumulation of zinc in plant seeds of genotypes of East-Kazakhstan Agricultural Research Institute collection in a polymetallic soil contamination have shown that this metal accumulates in small quantities, and its content does not exceed the maximum permissible concentration in the seeds of almost all genotypes, except varieties Nargis, Altai and Glubochanka (Figure 7).

This may be due to the fact that the content of the element in soil does not exceed MPC for soil or slightly exceeded. Despite this, in plant seeds of varieties Glubochanka and Altai accumulated amount of zinc is slightly above the MPC for wheat. The amount of zinc for 1.3-1.4 times higher than the maximum permissible concentration for grain in the seeds of varieties Altai and Zaulbinka and for 2.4 times greater than maximum permissible concentration in the seeds of variety Nargis.

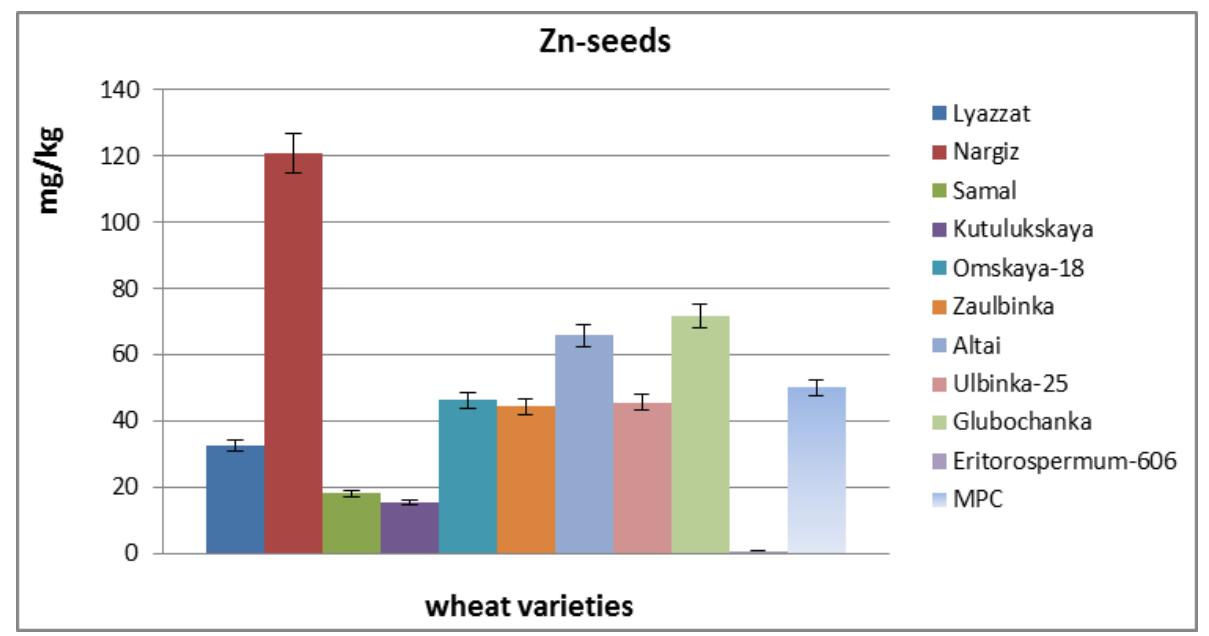

Figure 7. Zinc content in the seeds of different spring wheat genotypes of East-Kazakhstan Agricultural Research Institute collection

The study of cadmium accumulation in plant seeds of genotypes of East-Kazakhstan Agricultural Research Institute collection in a polymetallic soil contamination have shown that this metal accumulates in small quantities, and its content is slightly higher than the MPC for the grain in case of spring wheat variety Erythrospermum-606 (Figure 8). 


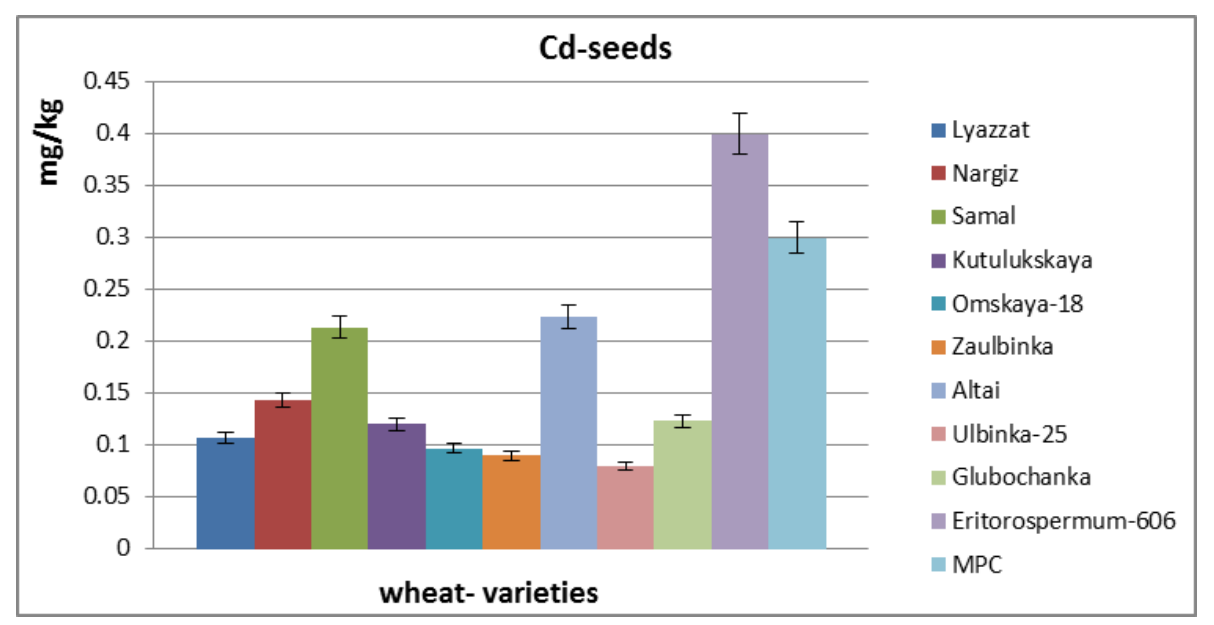

Figure 8. Cadmium content in seeds of different genotypes of East-Kazakhstan Agricultural Research Institute spring wheat collection

It should be noted that in the root zone soil content of cadmium is significant and exceeds MPC almost in all genotypes, except varieties Nargiz and Altay (Figure 6). Despite this, spring wheat seeds do not accumulate significant amounts of cadmium. The greatest amounts of cadmium accumulate seeds of variety Erythrospermum-606. Thus, the study of investigated heavy metals accumulation in the spring wheat seeds of East-Kazakhstan Agricultural Research Institute collection showed, that in terms of cadmium accumulation, the most resistant varieties of spring wheat are Ulbinka, Zaulbinka and Omskaya-18.

In terms of accumulation of zinc, the most resistant varieties are Samal and Kutulukskaya. In respect to varieties Kutulukskaya, this fact can be seen as a disadvantage, since zinc content in soil, where the roots of this variety plants inhabit, is slight. Seeds of this wheat variety depleted of necessary for nutrition element. For variety Samal, this fact can be considered as an advantage, since the soil layer, where this variety roots inhabit, the zinc content heightened and in spite of this seeds does not accumulate significant amounts of zinc.

Spring wheat varieties Ulbinka, Zaulbinka and Omskaya-18 can be recommended for further use in breeding for resistance to the accumulation of cadmium in the grain. Samal spring wheat varieties can be recommended for further use in breeding for resistance to the accumulation of zinc in the grain.

Among the varieties of spring wheat of East-Kazakhstan Agricultural Research Institute collection the harvest from the plots is largest from the varieties of spring wheat Ulbinka-25, Glubochanka, Erythrospermum-606 and Altay (Figure 9).

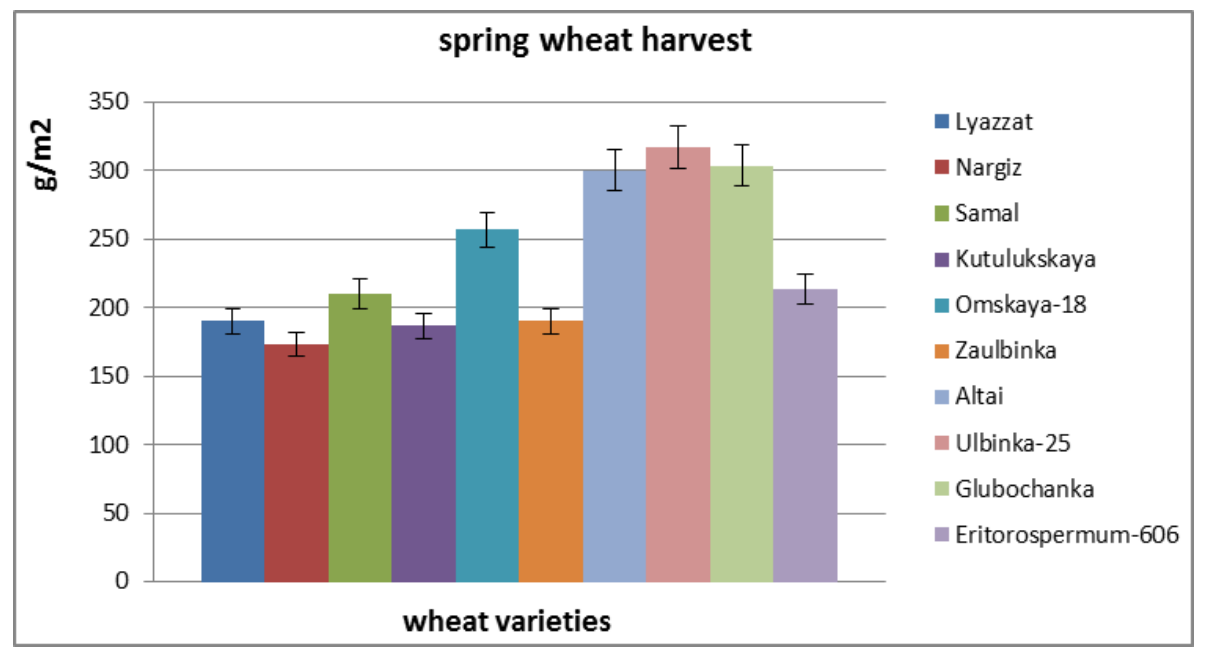

Figure 9. The harvest of different spring wheat genotypes of the East Kazakhstan Agricultural Research Institute collection, when grown in natural conditions of environmental pollution

In the case of the variety Ulbinka-25 together with high yield, this variety is also characterized by high indicators, as grain weight of main ear and as well as grain weight of lateral stems. In varieties Erythrospermum-606 and Altai, along with high yields also the highest values of grain weight of main ear and average indicators of grain weight of lateral stems revealed. Variety Glubochanka, although has an average the grain mass of the main ear and lateral stems, however, characterized by the highest rates of productive tillering, i.e. the number of productive lateral stems is big 
and probably therefore this variety has a higher overall crop yields.

The lowest yields in conditions of soil contamination with heavy metals demonstrate varieties: Lyazzat, Zaulbinka, Samal, Nargiz. The average yield compared with other spring wheat genotypes detected in varieties Kutulukskaya and Omskaya-18 (Figure 40).

Thus, the most harvest from plots has spring wheat varieties: Ulbinka-25, Glubochanka, Erythrospermum-616 and Altai. It is connected probably to a large number of grains per ear, high grain weight per ear, high productive tillering and good survival during the spring-summer growing season.

Varieties Ulbinka-25 and Omskaya-18 can be recommended for cultivation on soils contaminated with cadmium, as these varieties of spring wheat accumulate least of all cadmium in the seeds and at the same time are characterized by high yields and good survival during the spring-summer growing season in a polymetallic contamination of soil.

\section{Conclusions}

1. Spring wheat varieties Ulbinka, Zaulbinka and Omskaya-18 can be recommended for further use in breeding for resistance to the accumulation of cadmium in the grain.

2. Samal spring wheat varieties can be recommended for further use in breeding for resistance to the accumulation of zinc in the grain.

3. Varieties Ulbinka-25 and Omskaya-18 can be recommended for cultivation on soils contaminated with cadmium.

\section{REFERENCES}

[1] Alybaeva R.A. (2007). Evaluation of the ecological status of soils in Ust-Kamenogorsk. Bulletin of the KNU, environmental Series, 2 (21), 40-44.

[2] Wu Feibo, Zhang Guoping (2002). Genotypic variation in kernel heavy metal concentrations in barley and affected by soil factors, J.Plant Nutr., 25 (6), 1163-1173.

[3] Koval S.F. (1974). Investigation of the cell membranes properties and the resistance of plants by elution of electrolytes. News of the Sib. Branch of the Academy of Sciences of the USSR. Series of Biol. Sciences. 15 (3) 161-167.
[4] Dospekhov B.A. (1985) Methodology of field experience Moscow: Agro-industrial Publishing.

[5] Cosio C., Martinoia E., Keller C. (2006). Hyperaccumulation of cadmium and zink in Thlaspi caerulescens and Arabidopsis halleri at the leaf cellular level. Plant Physiol., 134 (2), 716-725.

[6] Broadhurst C. Leigh, Chaney Rufus L., Angle J. Scott, Maugel Timothy K., Erbe Eric F., Murphy Charles A. (2004). Simultaneous hyperaccumulation of nickel, manganese, and calcium in Alyssum leaf trichomes. Environ. Sci. and Technol., 38 (21), 5797-5802.

[7] Clemens S. (2007). Developing tools for phytoremediation: Towards a molecular understanding of plant metal tolerance and accumulation. Conference "Metals in Eastern and Central Europe: Health Effects, Sources of Contamination and Methods of Remediation" Prague, 8-10 Nov. 2006. Int J.Occup.Med. and Envir. Health., 14 (3), 235-239.

[8] Kupper H., MijovilovichA, Meyer-Klaucke W., Kroneck P.M.H. (2004). Tissue and age-dependent differences in the complexation of cadmium and zinc in the cadmium/zinc hyperaccumulator Thlaspi caerulescens (Ganges ecotype) revealed by X-ray absorption spectroscopy. Plant Physiol., 134 (2), 748-757.

[9] Plants in the extreme conditions of mineral nutrition. (1983) Ed. MJ Shkolnik and N. Alexeyeva-Popova-Leningrad: Science.

[10] Gamzikova OI, Barsukova VS, Koval SF. (1997). The ability to regulate wheat resistance to the presence of cadmium and nickel in the environment. Improv. Methodol. Agrochem.Research: Mater.Sci. Conf. Belgorod, Sep., 1995, M., 166-170.

[11] Altergot VF (1976) Principles of physiological studies and problems crop in Siberia. Physiology of plant resistance to continental climate, Novosibirsk, 4-14.

[12] Stevavic B., Sinzar I., Glisic O. (1998). Electrolyte leakage differences between poikilohydrous and homoiohydrous species of Gesneriaceae. Biologia Plantarum, 40 (2), 229-303.

[13] Kozhushko IN (1991) The study of the drought resistance of the global gene pool of spring wheat for breeding purposes. Leningrad.

[14] Loseva NL, Romanova TD, Ganev NL. (1985). To the question of energy function in plant resistance to thermal damage. Water and energy metabolism of plants. Kazan, 26-30.

[15] Knox R.E., Pozniak C.J., Clarke F.R., Clarke J.M., Houshmand S., and AK Singh RE. (2009). Chromosomal location of the cadmium uptake gene $(C d u 1)$ in durum wheat. Genome, 52 (9), $741-747$. 